\title{
Investigation of $\mathrm{La}_{1-x} \mathrm{Sr}_{x} \mathrm{CrO}_{3-\partial}(x \sim 0.1)$ as Membrane for Hydrogen Production
}

\author{
Yngve Larring ${ }^{1}$, Camilla Vigen ${ }^{2}$, Florian Ahouanto ${ }^{1}$, Marie-Laure Fontaine ${ }^{1}$, Thijs Peters ${ }^{1}$, \\ Jens B. Smith ${ }^{3}$, Truls Norby ${ }^{2}$ and Rune Bredesen ${ }^{1, *}$ \\ 1 SINTEF Materials and Chemistry, P.O. Box 124 Blindern, Oslo NO-0314, Norway; \\ E-Mails: yngve.larring@sintef.no (Y.L.); florian.ahouanto@sintef.no (F.A.); \\ marie-laure.fontaine@sintef.no (M.L.F.); thijs.peters@ sintef.no (T.P.) \\ 2 Centre for Materials Science and Nanotechnology, Department of Chemistry, University of Oslo, \\ FERMiO, Gaustadalleen 21, Oslo NO-0349, Norway; E-Mails: camilla.vigen@ smn.uio.no (C.V.); \\ truls.norby@kjemi.uio.no (T.N.) \\ 3 Statoil, Forskningsparken, Porsgrunn NO-3908, Norway; E-Mail:jbsm@statoil.com \\ * Author to whom correspondence should be addressed; E-Mail: rune.bredesen@ sintef.no; \\ Tel.: +47-93-811-279; Fax: +47-22-067-350.
}

Received: 1 August 2012; in revised form: 24 August 2012 / Accepted: 28 August 2012 / Published: 11 September 2012

\begin{abstract}
Various inorganic membranes have demonstrated good capability to separate hydrogen from other gases at elevated temperatures. Hydrogen-permeable, dense, mixed proton-electron conducting ceramic oxides offer superior selectivity and thermal stability, but chemically robust candidates with higher ambipolar protonic and electronic conductivity are needed. In this work, we present for the first time the results of various investigations of $\mathrm{La}_{1-x} \mathrm{Sr}_{x} \mathrm{CrO}_{3-\partial}$ membranes for hydrogen production. We aim in particular to elucidate the material's complex transport properties, involving co-ionic transport of oxide ions and protons, in addition to electron holes. This opens some new possibilities for efficient heat and mass transfer management in the production of hydrogen. Conductivity measurements as a function of $p \mathrm{H}_{2}$ at constant $p \mathrm{O}_{2}$ exhibit changes that reveal a significant hydration and presence of protons. The flux and production of hydrogen have been measured under different chemical gradients. In particular, the effect of water vapor in the feed and permeate gas stream sides was investigated with the aim of quantifying the ratio of hydrogen production by hydrogen flux from feed to permeate and oxygen flux the opposite way ("water splitting"). Deuterium labeling was used to unambiguously prove flux of hydrogen species.
\end{abstract}


Keywords: hydrogen transport membrane; proton permeation; oxygen permeation; water splitting

\section{Introduction}

Current concern about climate change has generated large efforts to reduce $\mathrm{CO}_{2}$ emissions. Hydrogen selective membranes are envisaged as a key enabling technology in various processes to lower energy consumption and for capturing $\mathrm{CO}_{2}$. Notably, inorganic hydrogen separation membranes have been studied for a long time for applications in so-called pre-combustion decarburization (PCDC) processes in power generation with $\mathrm{CO}_{2}$ capture. Since the various types of hydrogen separation membranes cover an operation window from ambient to $\sim 1000{ }^{\circ} \mathrm{C}$, tailor-making of process schemes, conditions and membrane properties are both a challenge and a great possibility for improving energy efficiency and creating sustainable operation. One may currently find various conceptual integration possibilities aiming to bridge the gap between process operation window and membrane properties [1,2]. An important aspect of this integration is to ensure sufficient driving force for the flux. For dense metallic or porous hydrogen separation membranes, the driving force for flux is proportional to $\boldsymbol{p}_{\mathbf{H}_{2}, \mathbf{f}}^{n}-\boldsymbol{p}_{\mathbf{H}_{2}, \mathbf{p}}^{\boldsymbol{n}}$ where $\mathrm{f}$ and $\mathrm{p}$ refer respectively to the feed and permeate side, and $n$ is typically between 0.5 and 1 for dense metal membranes and 1 for porous membranes. For these, the driving force is the magnitude in the difference between the two pressures, dominated by the largest one, at the feed side. For dense ceramic membranes, however, the flux can be various functions of the hydrogen partial pressures over the membrane, commonly proportional to $\ln \frac{p_{\mathrm{H}_{2}, \mathbf{f}}^{n}}{p_{\mathrm{H}_{2}, \mathbf{p}}^{n}}$, and in this case, it is beneficial to generate the highest possible ratio of the partial pressures of hydrogen over the membrane. Surface limiting effects may change these relationships and decrease the flux. In the concept of Norsk Hydro (now merged with Statoil), see Figure 1, a ceramic mixed conductor membrane for hydrogen separation is integrated at high temperature $\left(900-1000{ }^{\circ} \mathrm{C}\right)$ in the reforming reaction, where a high driving force is sustained by keeping the permeate side at a very low partial pressure of hydrogen by reaction with oxygen in air [3]. The purpose of the membrane is three-fold: (i) The membrane separates the two gas streams of natural gas (feed side) and air (permeate side). Hydrogen is transported from the feed side to the permeate side where it reacts with oxygen to generate heat to sustain the endothermic reforming process. The oxidation of hydrogen keeps the hydrogen partial pressure very low at the permeate side, which, as mentioned above, is particularly beneficial for the driving force for flux. (ii) Only the required amount of air required for heat generation is used, thus the permeate stream leaving the reactor is rich in $\mathrm{N}_{2}$. Hence, the membrane process enables $\mathrm{N}_{2}$ co-production that is required to dilute the hydrogen fuel for the subsequent gas turbine combustion process. (iii) Finally, the thin membrane acts as a heat exchanger material. 
Figure 1. PCDC process suggested by Statoil with integrated ceramic mixed conductor membrane [3].

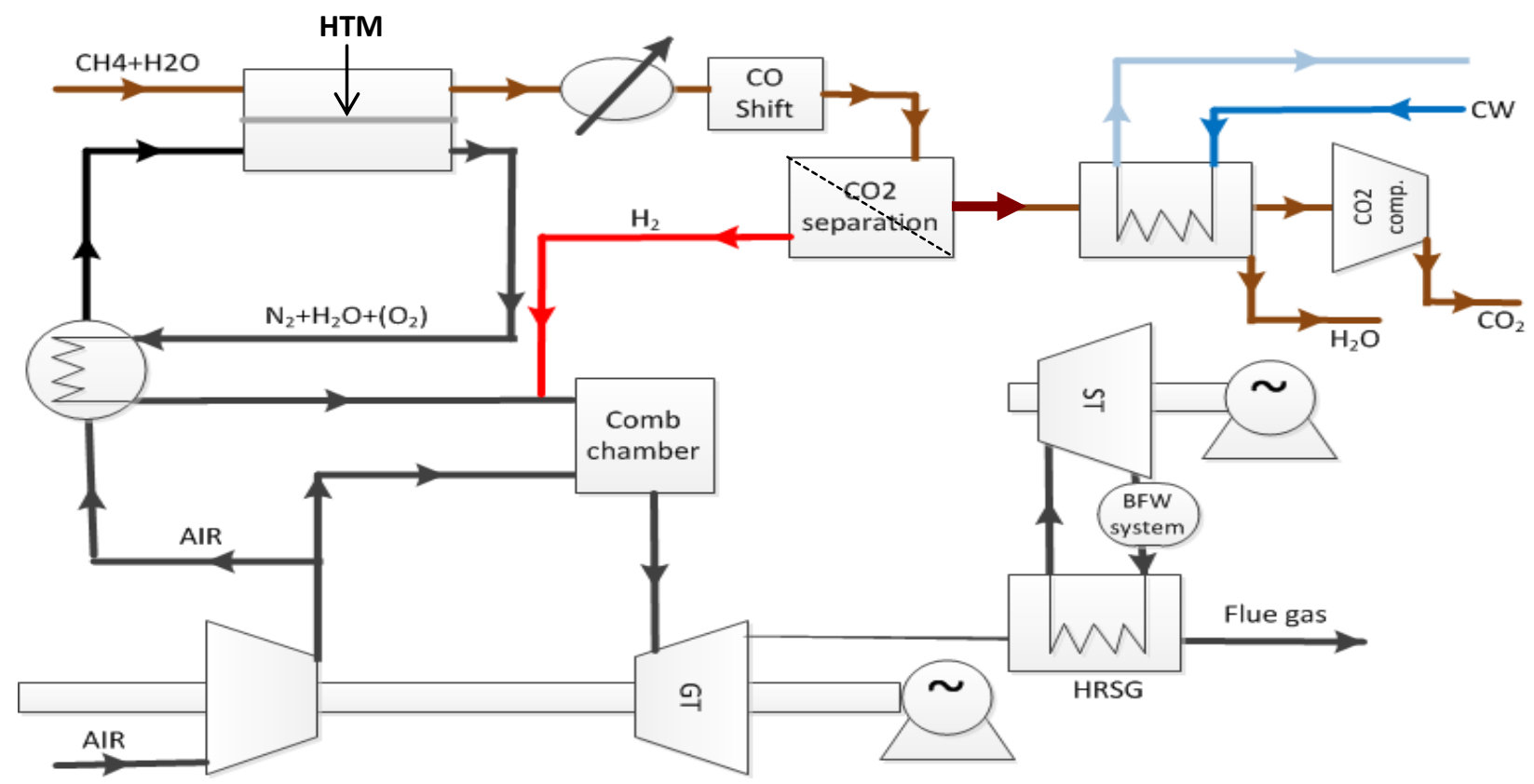

In dense ceramic hydrogen transport membranes (HTMs), one utilizes the mixed conductivity by electrons and protons to make the material permeable to hydrogen gas. The main difficulty for industrial deployment of HTMs lies in the identification of materials combining high proton concentrations and mobility at high temperature, high electron conductivity, and stability towards $\mathrm{CO}_{2}[4,5]$. To tackle these criteria, one may look for materials with mixed valence and modest band gaps in order to have electronic defects. But, first and foremost, one must look at proton concentration in terms of hydration thermodynamics. Nowadays, computational chemistry can predict hydration enthalpies quite reliably [6]. Moreover, there are some empirical correlations for classes of oxides. Hence, perovskites are shown to exhibit more favorable hydration thermodynamics the lower their structural tolerance factors and the more similar the electronegativities are of the A and B site cations [7-10]. In other words: the more stable the perovskite structure, the fewer the protons at high temperature; the material prefers oxygen vacancies as positive charge carriers charge compensating acceptor dopants, and exhibits essentially oxide ion transport.

The prime candidates for HTMs early on were based on $\mathrm{SrCeO}_{3}[11]$ and related perovskites. Their composites with metals, such as Pt (for higher electronic transport) have also been investigated. As $\mathrm{SrCeO}_{3}$ and related perovskites show poor thermodynamic stability and high reactivity with $\mathrm{CO}_{2}$, there has been a long search for new and more stable materials, preferably without $\mathrm{Sr}$ or $\mathrm{Ba}$ as main components, in order to have sufficient stability towards acidic gases like $\mathrm{CO}_{2}$ [5]. At present, a few new materials have emerged as promising candidates, such as $\mathrm{La}_{6} \mathrm{WO}_{12}$, with stable compositions in the range $\mathrm{La}_{6-x} \mathrm{WO}_{12-3 x / 2}(6-x=5.3-5.7)$ [12].

In the search of potential materials for their PCDC process, Statoil patented a range of alternative, stable perovskites as HTMs [13] and suggested how they could be used in natural gas-fired power plants with carbon capture [14]. One of the materials was based on $\mathrm{LaCrO}_{3}$. The choice may be surprising because this perovskite should contain few protons according to the aforementioned correlations, which predict $\mathrm{LaCrO}_{3}$ to have an endothermic hydration enthalpy of $12 \mathrm{~kJ} / \mathrm{mol}$. The 
argument in favor of this oxide was that the three d-electrons in $\mathrm{Cr}^{3+}$ make this ion particularly stable in an octahedral crystal field, favoring a filled oxygen lattice with protons (as $\mathrm{OH}^{-}$ions) over oxygen vacancies to a larger extent than expected from the general trend. Statoil optimized the composition for sinterability, developed porous tubular supports with dense thin layers of the material, and tested their use for hydrogen extraction. The hydration and hydrogen transport were investigated in collaborative projects with the University of Oslo and SINTEF over a number of years. During the work, it has become clear that the transport properties utilized in the PCDC process are more complex than anticipated. The ionic transport in the material appears to have contributions both from oxide ions and protons. This feature adds an interesting side effect of the membrane related to the operation condition in Figure 1; namely that the membrane also contributes to partial oxidation and steam generation at the feed side by transporting oxygen from the permeate side, creating heat on the reforming side as well. The significance of this effect has not yet been fully explored, and should be a subject of a separate study; but it is interesting to note that the effect could reduce the need for the addition of steam to the feed stream since it is internally generated.

In this study, the transport properties, including hydrogen species of ceramic membranes of Sr-substituted $\mathrm{LaCrO}_{3}$ (LSC), are reported for the first time. We summarize the work done with LSC membranes - including hydrogen permeation as well as concentration and mobility of protons - based on formerly undisclosed results and new measurements. We shall see that LSC does indeed dissolve modest amounts of protons and exhibits proton conductivity mixed with p-type electronic and oxide ion conductivities, all depending on temperature, $p \mathrm{O}_{2}$, and $p \mathrm{H}_{2} \mathrm{O}$. Production of hydrogen using such a material as a membrane towards a hydrogen-rich mixture stems partly from mixed protonic-electronic conduction, but may have a contribution from splitting of any water vapor in the permeate sweep gas, based on mixed oxide ion-electron conduction, and the two phenomena may be difficult to distinguish.

\section{Brief Review of Undoped and Acceptor-Substituted $\mathrm{LaCrO}_{3}$}

\subsection{Properties and Applications}

Lanthanum chromite, $\mathrm{LaCrO}_{3}$, is a refractory oxide with melting point of $2430{ }^{\circ} \mathrm{C}$, taking on a perovskite-related structure with orthorhombic symmetry (Pnma, space group 62) [15]. It exhibits a small range of cation non-stoichiometry, as indicated in the phase diagram [16], and it can be substituted with a number of homo- and heterovalent cations on both the A (La) and B (Cr) sites. Of greatest interest is the effect of acceptor substitution by alkaline earth cations-notably $\mathrm{Ca}^{2+}$ or $\mathrm{Sr}^{2+}$ - for $\mathrm{La}^{3+}[17,18]$, causing charge compensation by oxygen vacancies at low $p \mathrm{O}_{2}$ and electron holes at high $\mathrm{pO}_{2}$ [19-21]. For this reason, Ca- and Sr-substituted $\mathrm{LaCrO}_{3}$-hereafter LCC and LSC, respectively - exhibit high p-type electronic conductivity under oxidizing and moderately reducing conditions, falling off under more reducing conditions, but still with dominating p-type electronic conductivity well above $1 \mathrm{~S} / \mathrm{cm}[19,22,23]$. This, along with its great stability towards oxidation as well as reduction, has made it of interest as an interconnect material in SOFCs, where it must exhibit electronic conductivity, be gas tight in order to separate the fuel and oxidant, and preferably not conduct oxide ions $[19,24]$. 
It was pointed out early on that the presence of oxygen vacancies would give considerable oxide ion conductivity and permeability of oxygen in LCC and LSC [22], but it appeared that the thickness of the interconnect and the rather slow surface kinetics of $\mathrm{LaCrO}_{3}$-based materials made this a minor problem [30].

It is very difficult to sinter $\mathrm{LaCrO}_{3}$-based ceramics to high density, and a lot of research has been invested into overcoming this bottleneck, using, for instance, sintering aids [25]. Interconnects of these materials also suffer from $\mathrm{Cr}$ evaporation, notably by hexavalent chromium oxohydroxides [26], which poisons SOFC cathodes by the deposition of $\mathrm{Cr}$ oxides at the electrocatalytic triple-phase boundary sites between strontium-substituted $\mathrm{LaMnO}_{3}$ (LSM) cathodes and YSZ electrolytes [27]. Additional weaknesses comprise moderate mechanical properties, chemical expansion by reduction, limited thermal conductivity, and high costs of machining. For these reasons, $\mathrm{LaCrO}_{3}$-based interconnects are now for the most part being replaced by metallic interconnects-enabled by the reduced temperatures of operation of modern SOFCs [27-29].

\subsection{Defect Structure}

$\mathrm{LaCrO}_{3}$ compensates acceptor-dopants with electron holes under oxidizing conditions and oxygen vacancies under reducing conditions, accompanied by corresponding increases the oxygen ion and p-type electronic conductivities. Studies, where oxygen non-stoichiometry has been measured as a function of oxygen partial pressure $\left(p \mathrm{O}_{2}\right)$ by means of thermogravimetry, have been conducted for $\mathrm{LaCrO}_{3}$ with various dopants, doping levels and temperatures [20,21]. Mizusaki et al. [20] reported that the oxygen non-stoichiometry $\delta$ for $\mathrm{La}_{1-x} \mathrm{Sr}_{x} \mathrm{CrO}_{3-\delta}(x=0.1-0.3)$ was close to zero for $p \mathrm{O}_{2}>10^{-5}$ and eventually reached $x / 2$ with decreasing $p \mathrm{O}_{2}$. These $p \mathrm{O}_{2}$ regimes represent two limiting conditions where the acceptor is predominately charge-compensated by electron holes (i.e., $\left[\mathrm{h}^{\bullet}\right]=\left[\mathrm{Sr}_{\mathrm{La}}^{/}\right]$) and oxygen vacancies (i.e., $2\left[\mathrm{v}_{\mathrm{o}}^{\bullet}\right]=\left[\mathrm{Sr}_{\mathrm{La}}^{/}\right]$), respectively. Moreover, the limiting $p \mathrm{O}_{2}$, at which oxygen vacancies and electron holes are equally dominant, shifts to higher $p \mathrm{O}_{2}$ with increasing doping levels and temperatures. The formation of oxygen vacancies at the cost of electron holes can, in Kröger-Vink notation, be written:

$$
2 h^{\bullet}+O_{o}^{x}=v_{o}^{\bullet \bullet}+1 / 2 O_{2}(g)
$$

The equilibrium constant for this reaction is given by:

$$
K_{\mathrm{v}_{\mathrm{o}}}=\frac{\left[\mathrm{v}_{\mathrm{o}}^{\bullet \bullet}\right]{p_{\mathrm{O}_{2}}}^{1 / 2}}{\left[\mathrm{~h}^{\bullet}\right]^{2}\left[\mathrm{O}_{\mathrm{o}}^{x}\right]}
$$

and Mizusaki et al. estimated the standard formation enthalpy of oxygen vacancies according to this reaction to $303 \mathrm{~kJ} / \mathrm{mol}$ for $x=0.1$. A similar behavior was observed for $\operatorname{LaCr}_{(1-x)} \operatorname{Mg}_{x} \mathrm{O}_{3-\delta}$ [21], where the corresponding enthalpy was seemingly independent of dopant concentration and estimated at $272 \mathrm{~kJ} / \mathrm{mol}$ for $x=0.02-0.1$.

From the limiting electroneutrality condition, the concentration of electron holes will be independent of $\mathrm{pO}_{2}$ when the acceptor is charge-compensated by electron holes, since it follows from Equation (2) that it exhibits a $\mathrm{pO}_{2}{ }^{1 / 4}$-dependecy when the acceptor is charge-compensated by oxygen vacancies. The defect concentrations as a function of $p \mathrm{O}_{2}$ are illustrated in Figure 2. Due to higher 
mobility of electron holes in general compared to ionic defects, the total conductivity will also exhibit the $p \mathrm{O}_{2}$-dependencies of the electron holes [22,23].

Figure 2. Example of defect concentrations for LSC with 1 mol\% acceptor substitution as a function of $p \mathrm{O}_{2}$ at constant $\mathrm{pH}_{2} \mathrm{O}$.

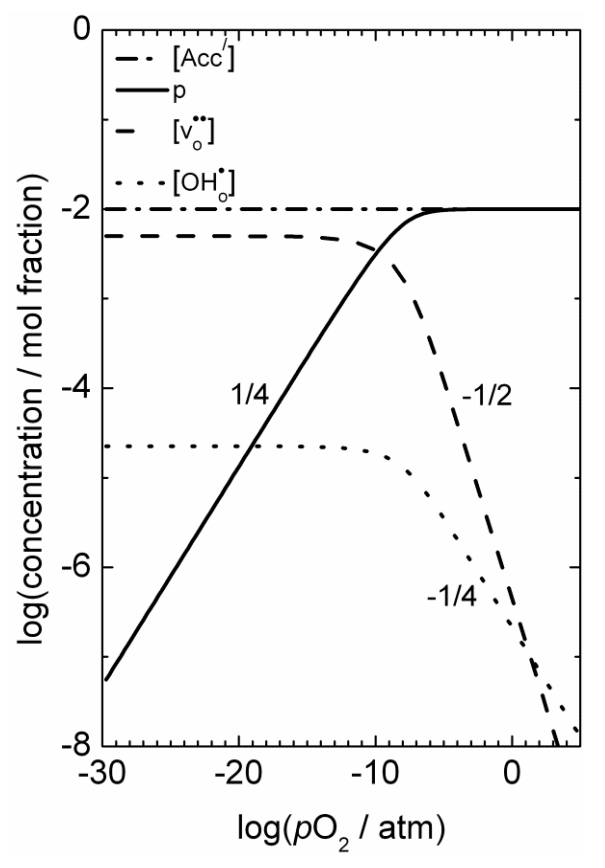

\subsection{A Theoretical Evaluation of Protons in LSC}

Hydration of oxygen vacancies in oxides occurs according to:

$$
\mathrm{H}_{2} \mathrm{O}+\mathrm{v}_{\mathrm{o}}^{\bullet \bullet}+\mathrm{O}_{\mathrm{o}}^{x}=2 \mathrm{OH}_{\mathrm{o}}^{\bullet}
$$

with the corresponding equilibrium constant:

$$
K_{\text {hydr }}=\frac{\left[\mathrm{OH}_{\mathrm{o}}^{\bullet}\right]^{2}}{\left[\mathrm{O}_{\mathrm{o}}^{\mathrm{x}}\right]\left[\mathrm{v}_{\mathrm{o}}^{\bullet \bullet}\right] p_{\mathrm{H}_{2} \mathrm{O}}}
$$

When protons are included, the overall electroneutrality condition of LSC can be approximated by:

$$
2\left[\mathrm{v}_{\mathrm{o}}^{\bullet}\right]+\left[\mathrm{OH}_{\mathrm{o}}^{\bullet}\right]+\mathrm{p}=\left[\mathrm{Sr}_{\mathrm{La}}^{/}\right]
$$

As can be deduced from Equations (1) and (3) and seen in Figure 2, the concentration of protons increases with decreasing $p \mathrm{O}_{2}$. From Equation (4), it follows that the concentration of protonic defects as a function of water vapor partial pressure $\left(p \mathrm{H}_{2} \mathrm{O}\right)$ is proportional to $p \mathrm{H}_{2} \mathrm{O}^{1 / 2}$ if electron holes or oxygen vacancies are the dominating charge compensating defects (and thus independent of $p \mathrm{H}_{2} \mathrm{O}$ ). If protons become the dominating charge compensator, the minor concentration of oxygen vacancies becomes proportional to $\mathrm{H}_{2} \mathrm{O}^{-1}$, while the concentration of electron holes, via Equation 2, becomes proportional to $\mathrm{pH}_{2} \mathrm{O}^{-1 / 2}$.

To the best of our knowledge, there have been no significant reports of protons in LSC until this study, and, as mentioned above, the correlation between the enthalpy of the hydration of oxygen vacancies and the stability of the perovskite does not predict that hydration is favorable at all, while the 
three d-electrons of $\mathrm{Cr}^{3+}$ suggests that LSC may be an exception. The defect concentrations as a function of water vapor partial pressure are illustrated in Figure 3, based on a moderately favorable hydration enthalpy. One may note that at high $\mathrm{pH}_{2} \mathrm{O}$, hydration and the presence of protons should be detectable as a decrease in the p-type electronic conductivity as a function of $p \mathrm{H}_{2} \mathrm{O}$.

Figure 3. Example of defect concentrations for LSC with 1 mol\% acceptor substitution as a function of $p \mathrm{H}_{2} \mathrm{O}$ at constant $p \mathrm{O}_{2}$.

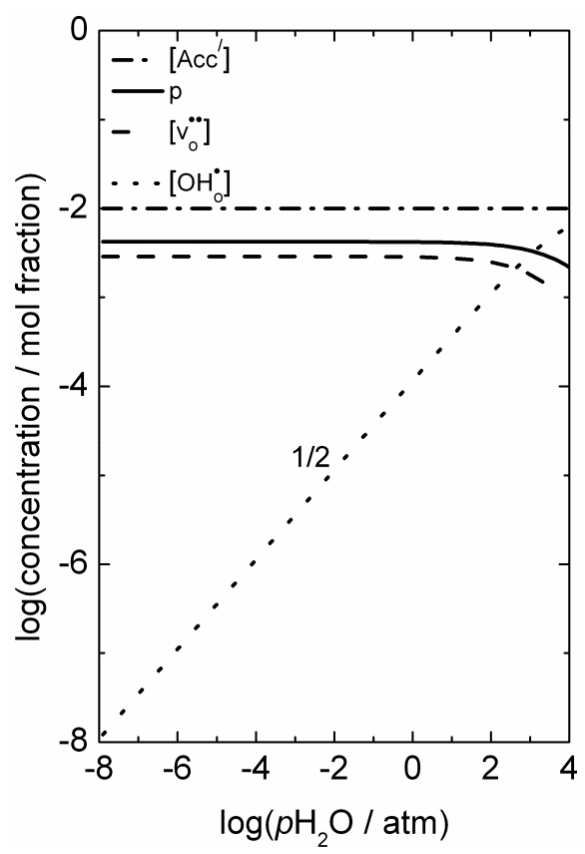

\subsection{Transport Properties}

The electron holes in $\mathrm{LaCrO}_{3}$ appear to behave as small polarons localized to the Cr-site, and the hole mobility exhibits a small activation energy. Consequently, the p-type conductivity is also activated $\left(\sigma \propto(1 / T) e^{-\left(E_{a} / R T\right)}\right)$, and in the region where the holes are dominating and their concentration given by the constant concentration of acceptors, $E_{\mathrm{a}}$, is given only by that of the mobility. Karim and Aldred [31] reported that the electrical conductivity of $\mathrm{La}_{1-x} \mathrm{Sr}_{x} \mathrm{CrO}_{3}$ increased from the order of $10^{-2} \mathrm{~S} / \mathrm{cm}$ at temperatures above $1000{ }^{\circ} \mathrm{C}$ and $p \mathrm{O}_{2}=1$ atm for $x=0$, to values two orders of magnitude higher for high values of $\mathrm{x}$ up to the maximum level $(x=0.4)$. The electron hole activation energy was estimated at $0.192 \mathrm{eV}$ for the undoped chromite $(x=0)$, and decreased with increasing acceptor-concentrations to $0.113 \mathrm{eV}$ for $x=0.4$.

$\mathrm{LaCrO}_{3}$ is also an oxide ion conductor when acceptor doped. Oxygen vacancy diffusion coefficients in the order of $10^{-6}-10^{-5} \mathrm{~cm}^{2} / \mathrm{s}$ were calculated from electrical measurements of $\mathrm{LaCrO}_{3}$ with varying dopants and doping levels $(0.1-0.35 \mathrm{~mol} \%)$ at temperatures $900-1100{ }^{\circ} \mathrm{C}$ [22]. Based on electrochemical methods, Yokokawa et al. [32] estimated a lower vacancy diffusion coefficient in the order of $10^{-7} \mathrm{~cm}^{2} / \mathrm{s}$ at $1000{ }^{\circ} \mathrm{C}$, in agreement with calculations by Van Hassel et al., based on oxygen permeation [33]. Later on, Kawada et al. [34] revisited this method and estimated an oxygen vacancy diffusion coefficient in the order of $10^{-5} \mathrm{~cm}^{2} / \mathrm{s}$. The lower values of the oxygen vacancy diffusion coefficients reported earlier were mainly explained by an underestimation of the oxygen non-stoichiometry in the high $p \mathrm{O}_{2}$ region. 


\section{Results and Discussion}

\subsection{Conductivity vs. $\mathrm{pH}_{2} \mathrm{O}$}

Figure 4 presents the total a.c. conductivity of $\mathrm{La}_{0.9} \mathrm{Sr}_{0.1} \mathrm{CrO}_{3-\delta}$ as a function of $p \mathrm{H}_{2} \mathrm{O}$ in reducing atmospheres at temperatures from 300 to $800{ }^{\circ} \mathrm{C}$. Each isotherm is made by diluting a mixture with fixed $p \mathrm{H}_{2} / p \mathrm{H}_{2} \mathrm{O}$ ratio with dry Ar, thus keeping $p \mathrm{O}_{2}$ essentially constant, while changing $p \mathrm{H}_{2} \mathrm{O}$ (and $p \mathrm{H}_{2}$ ). The values of $p \mathrm{O}_{2}$ vary from $3 \times 10^{-17}$ and $4 \times 10^{-21}$ atm (depending of $p \mathrm{H}_{2} / p \mathrm{H}_{2} \mathrm{O}$ ratio) at $800{ }^{\circ} \mathrm{C}$ to $2 \times 10^{-42}$ atm at $300{ }^{\circ} \mathrm{C}$, and under these conditions we may assume that the acceptor dopant is, to a first approximation, charge-compensated by oxygen vacancies. This assumption is in agreement with the higher p-type electronic conductivity observed at $p \mathrm{O}_{2}=3 \times 10^{-17}$ than at $p \mathrm{O}_{2}=4 \times 10^{-21}$ atm at $800{ }^{\circ} \mathrm{C}$, as the concentration of electron holes will increase with increasing $p \mathrm{O}_{2}$ when in the minority. Still, electron holes dominate the total conductivity, due to higher mobility than for ionic defects.

Figure 4. Total a.c. conductivity as a function of water vapor partial pressure for $\mathrm{La}_{0.9} \mathrm{Sr}_{0.1} \mathrm{CrO}_{3-\delta}$ in reducing atmospheres.

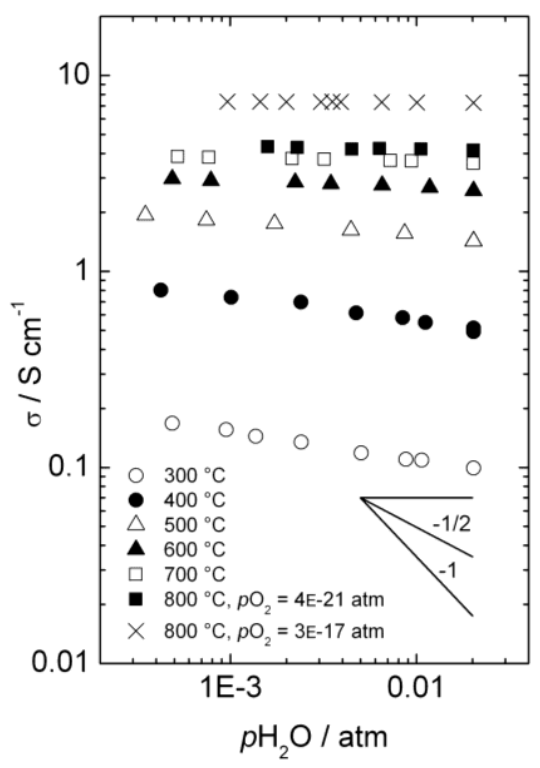

Below approximately $600{ }^{\circ} \mathrm{C}$, the conductivity decreases with increasing $p \mathrm{H}_{2} \mathrm{O}$, reflecting a decrease in the concentration of electron holes as protonic defects are introduced in significant numbers compared to the dominating oxygen vacancies.

By assuming that oxygen vacancies and protons are the dominating charge compensators $\left(2\left[\mathrm{v}_{\mathrm{o}}^{\bullet}\right]+\left[\mathrm{OH}_{\mathrm{o}}^{\bullet}\right]=\left[\mathrm{Sr}_{\mathrm{La}}^{/}\right]\right)$, the equilibrium constant of Equation (3), $K_{\text {hydr }}$, was extracted from the fit of the conductivity curves for each temperature. The results are presented in a van 't Hoff plot (Figure 5), and linear regression of $\ln K_{\text {hydr }}$ as a function of $1 / T$ yields standard enthalpy and entropy changes of the hydration reaction of $-70 \mathrm{~kJ} / \mathrm{mol}$ and $-90 \mathrm{KJ} / \mathrm{mol}$, respectively. The equilibrium constant extracted from conductivity measurements at $300{ }^{\circ} \mathrm{C}$ was excluded in this fitting, due to significant deviation from the values obtained at higher temperatures, likely a consequence of slow kinetics. The exothermic hydration enthalpy of $-70 \mathrm{~kJ} / \mathrm{mol}$ for $\mathrm{La}_{0.9} \mathrm{Sr}_{0.1} \mathrm{CrO}_{3-\delta}$ is far from the endothermic expected, based on the already mentioned empirical correlation [7-10], and the aforementioned crystal field stabilization 
of the d-electrons in fully $v s$. only partially occupied octahedra of the perovskites is an interesting input to understanding this and the many other variations from the correlation.

Figure 5. Van 't Hoff plot of hydration equilibrium constant $K_{\text {hydr }}$ for $\mathrm{La}_{0.9} \mathrm{Sr}_{0.1} \mathrm{CrO}_{3-\delta}$ corresponding to conductivity data of Figure 4.

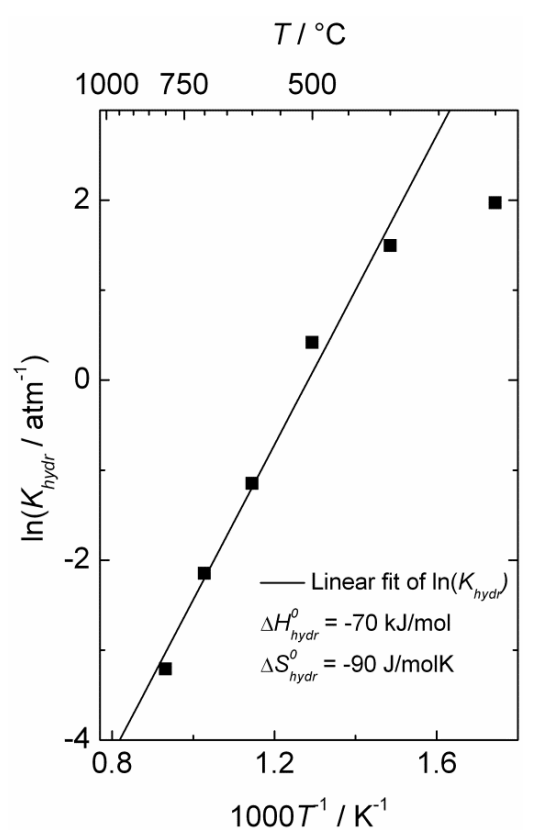

\subsection{Estimated Defect Concentrations and Partial Conductivities}

With the parameters obtained by curve-fitting of the hydration equilibrium constant, we have estimated the concentrations of the defects in $\mathrm{La}_{0.9} \mathrm{Sr}_{0.1} \mathrm{CrO}_{3-\delta}$ in wet reducing atmospheres (i.e., $p \mathrm{H}_{2} \mathrm{O}=0.025$ atm, $\left.p \mathrm{H}_{2}=1 \mathrm{~atm}\right)$. All charge carriers were assumed to follow an activated transport process, i.e., $\sigma_{i}=z_{i} e c_{i} u_{0, i} \frac{1}{T} \mathrm{e}^{-\Delta H_{\mathrm{mob}, i} / R T}$. For oxygen vacancies, the pre-exponential factor of mobility, $u_{0, v o}$, and the enthalpy of mobility, $\Delta H_{m o b, v o}$, were set to $200 \mathrm{~cm}^{2} \mathrm{~K} / \mathrm{Vs}$ and $90 \mathrm{~kJ} / \mathrm{mol}$, respectively, in accordance with oxygen vacancy diffusion coefficients obtained at temperatures from $950-1100{ }^{\circ} \mathrm{C}$ for $\mathrm{La}_{0.8} \mathrm{Sr}_{0.2} \mathrm{Cr}_{0.95} \mathrm{Ni}_{0.05} \mathrm{O}_{3-\delta}$ [30]. For protons, the pre-exponential factor of mobility, $u_{0, O H}$, was set to $13 \mathrm{~cm}^{2} \mathrm{~K} / \mathrm{Vs}$, in accordance with values obtained for similar perovskite oxides from [9] and the data set of [8], and the enthalpy of mobility, $\Delta H_{m o b, O H}$, was set to $60 \mathrm{~kJ} / \mathrm{mol}$, from the empirical $2 / 3$ of the value for oxygen vacancies [8]. The pre-exponential factor of hole mobility, $u_{0, h}$, and the enthalpy of hole mobility, $\Delta H_{m o b, h}$, were set in accordance with Weber et al. [35] to $200 \mathrm{~cm}^{2} \mathrm{~K} / \mathrm{Vs}$ and $12.5 \mathrm{~kJ} / \mathrm{mol}$, respectively. Furthermore, it was assumed that the nominal $\mathrm{Sr}$ acceptor level was effective.

The estimated defect concentrations and partial conductivities are presented as a function of inverse temperature in Figures 6 and 7, respectively.

The estimated proton conductivity reaches approximately $5 \times 10^{-4} \mathrm{~S} / \mathrm{cm}$ at $800{ }^{\circ} \mathrm{C}$, while the oxygen vacancies reach a conductivity in the order of $10^{-3} \mathrm{~S} / \mathrm{cm}$. Figure 7 also illustrates that the electron hole conductivity dominates the total conductivity, even when electron holes are minority defects under reducing conditions. The bends in the conductivity curves are the result of the changeover to a proton-dominated defect structure at lower temperatures. 
Figure 6. Estimated defect concentrations as a function of inverse temperature for $\mathrm{La}_{0.9} \mathrm{Sr}_{0.1} \mathrm{CrO}_{3-\delta}$ in wet, reducing atmospheres $\left(p \mathrm{H}_{2}=1\right.$ atm, $p \mathrm{H}_{2} \mathrm{O}=0.025$ atm $)$.

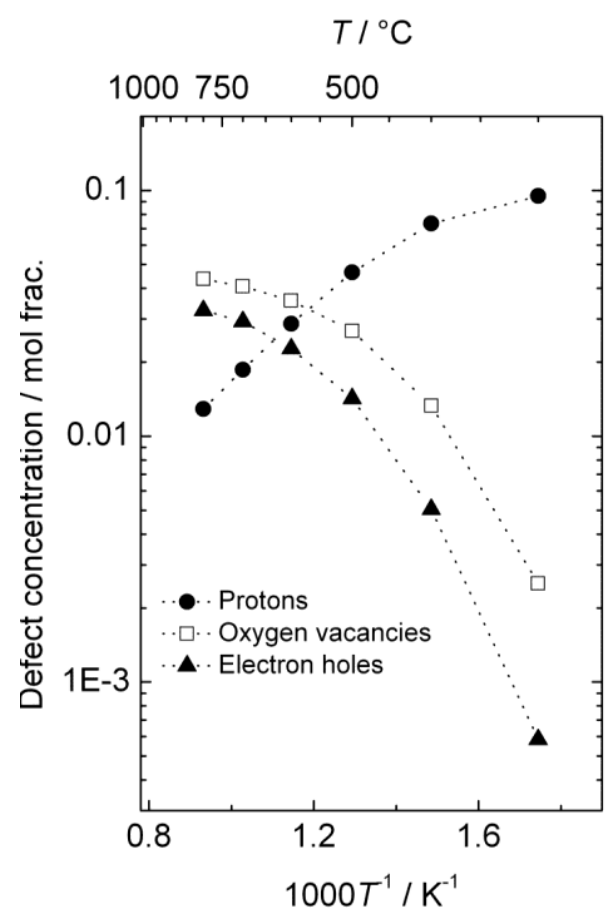

Figure 7. Estimated total and partial conductivities as a function of inverse temperature for $\mathrm{La}_{0.9} \mathrm{Sr}_{0.1} \mathrm{CrO}_{3-\delta}$ in wet reducing atmospheres $\left(p \mathrm{H}_{2}=1 \mathrm{~atm}, p \mathrm{H}_{2} \mathrm{O}=0.025 \mathrm{~atm}\right)$.

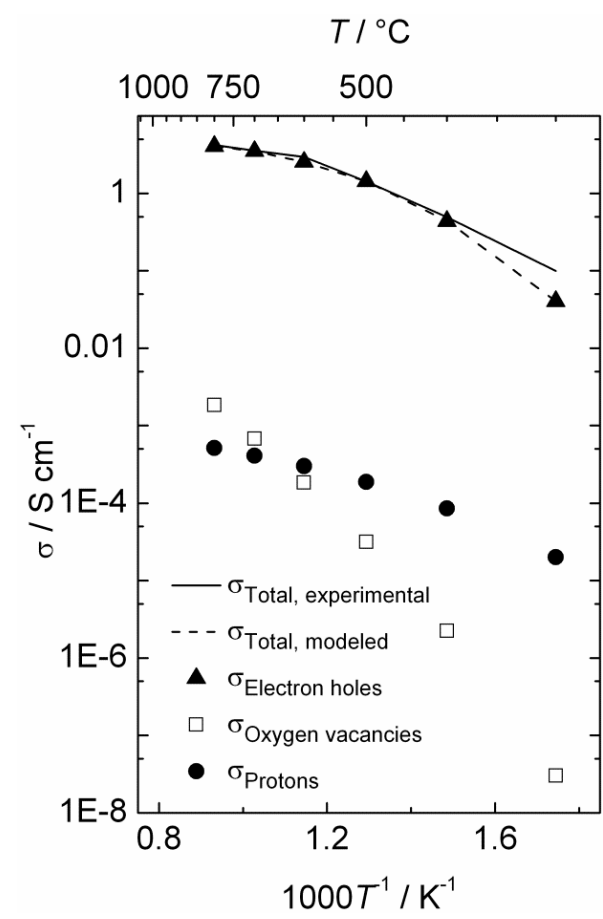

Based on the estimated partial conductivities, we may estimate the ambipolar proton-hole conductivity of $\mathrm{La}_{0.9} \mathrm{Sr}_{0.1} \mathrm{CrO}_{3-\delta}$ from

$$
\sigma_{\text {H ambipolar }}=\frac{\sigma_{h} \sigma_{H^{+}}}{\sigma_{\text {Total }}}
$$


and it is limited by the lower of the two partial conductivities. In LSC, proton conductivity is orders of magnitude lower than that of electron holes, thereby limiting this ambipolar conductivity.

\subsection{Measurements of Hydrogen Production with Disk-Shaped Membranes}

Hydrogen production measurements - interpreted as apparent hydrogen flux — were performed on disk-shaped LSC membranes of approximately $0.5 \mathrm{~mm}$ thickness, prepared with various sintering agents (see Table 1). They showed an initial apparent flux of $0.04-0.02 \mathrm{~mL} \mathrm{~min} \mathrm{~m}^{-1} \mathrm{~cm}^{-2}$, which decreased over some $50-200 \mathrm{~h}$ at $1000{ }^{\circ} \mathrm{C}$ to final values of $0.02-0.01 \mathrm{~mL} \mathrm{~min}^{-1} \mathrm{~cm}^{-2}$ at $1000{ }^{\circ} \mathrm{C}$ in $50 \%$ humidified $\mathrm{H}_{2}$ on the feed side and humidified argon at the permeate side (see Figure 8). The initially high apparent flux may be related to an initially high concentration of intrinsic defects created under the very high sintering temperature. The decrease in apparent flux may alternatively be related to the relaxation and decrease in surface catalytic activity of the polished surfaces during initial operation at elevated temperatures.

Figure 8. Hydrogen production plotted as apparent hydrogen $\left(\mathrm{H}_{2}\right)$ flux (leakage corrected) as a function of time at $1000{ }^{\circ} \mathrm{C}$ using $50 \%$ wet $\mathrm{H}_{2}$ as feed gas for different LSC samples of thickness around $0.5 \mathrm{~mm}$ (see Table 1). Wet permeate gas is used for most of the experiment, except for a short period with dry permeate (DP), with a steep decrease in the hydrogen production rate.

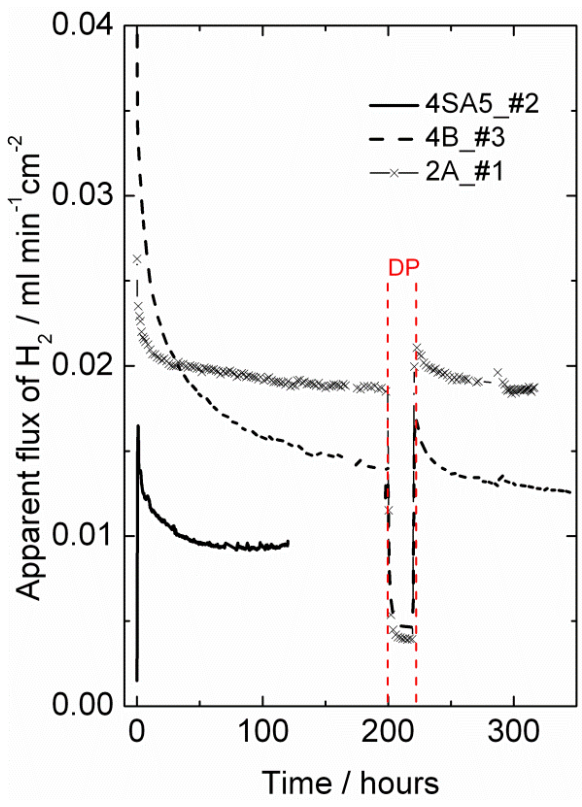

The effect of different types of gradients was further investigated in order to separate situations with only hydrogen (proton-hole) transport and cases where oxygen transport, and hence water splitting, contribute to the hydrogen production. Four different gradients are shown in Figure 9, where all have $50 \%$ or $10 \%$ hydrogen on the feed side and argon on the permeate side. The only difference is that the gases are either wet or dry. Accordingly, the following effects can be seen:

Dry feed/Wet permeate (DF/WP) gives the highest hydrogen production. This can be attributed to a high level of water splitting on the permeate side, combined with a high driving force for transport of oxygen from permeate to feed. Wet feed/wet permeate (WF/WP) gives a slightly lower hydrogen 
production. One can expect the driving force for water splitting to be lower, since the difference in $p\left(\mathrm{O}_{2}\right)$ is less. Wet feed/dry permeate (WF/DP) gives yet lower hydrogen production. In this case we have no possibility of water splitting and the hydrogen must come from ambipolar proton transport. Dry feed/dry permeate (DF/DP) gives the lowest hydrogen production when comparing cases with equally amounts of hydrogen on the feed side. Here, we are probably additionally limited by the hydration and concentration of protons in the oxide.

It is noteworthy that what we believe is water splitting from ambipolar oxygen transport and what we believe is ambipolar hydrogen transport both appear to have similar and rather high activation energies. As we shall see later, this is possibly related to both being limited by surface kinetics of the polished disk samples used.

Figure 9. Hydrogen production plotted in terms of an apparent hydrogen $\left(\mathrm{H}_{2}\right)$ flux as a function of inverse temperature for sample 4SA5_\#2 in 4 different gradients using dry (D) or Wet (W) Feed (F) and Permeate (P) gas.

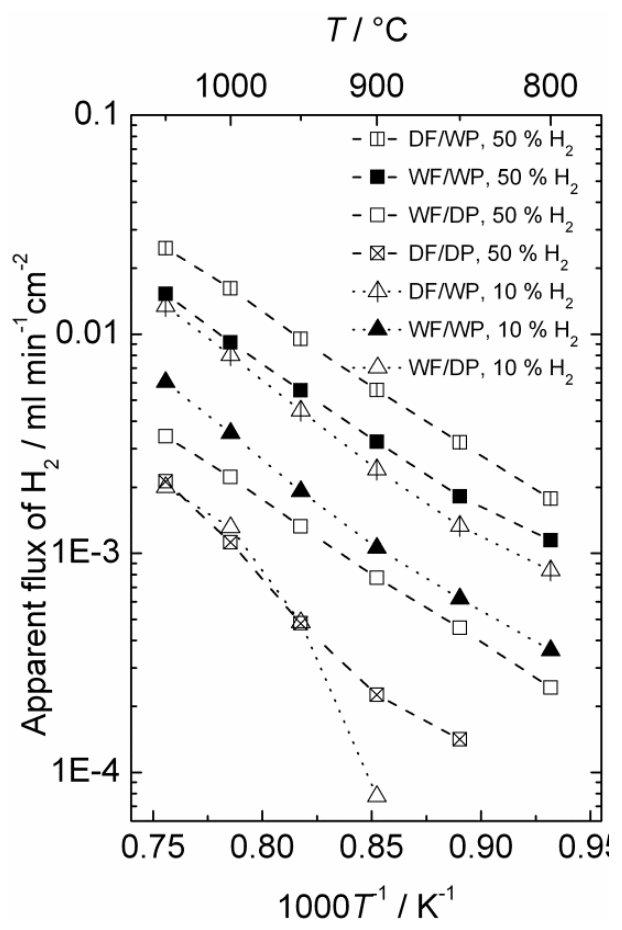

\subsection{Measurements of Hydrogen Production with Disk-Shaped Membranes under Pressurized Conditions}

Hydrogen production measurements were performed up to 5 bars on both feed and permeate sides, using high steam contents on both sides, in order to increase the proton concentration and reduce the vacancy concentration in LSC by water incorporation, according to Equation (3). Results for $1000{ }^{\circ} \mathrm{C}$ are plotted on Figure 10. The apparent hydrogen flux is largely independent of total pressure and of steam content, see Figure 10a, c, and instead the amount of hydrogen in the feed plays a somewhat larger role-see Figure 10b. These observations do not immediately lend support to either proton or oxygen transport; the hydrogen production can well come from both hydrogen flux and water splitting. We note, however, that the values of apparent flux are qualitatively similar to those done at atmospheric pressure and normal wet gases above. 
Figure 10. Measured apparent $\mathrm{H}_{2}$ flux, and the same corrected for leakage using the measured He flux, for sample 4B_\#3 at $1000{ }^{\circ} \mathrm{C}$, plotted as a function of (a) total feed pressure using $\mathrm{H}_{2} / \mathrm{He} / \mathrm{N}_{2} /$ steam $=20: 10: 50: 20$ on the feed side and $\mathrm{Ar} /$ steam $=80: 20$ on the permeate side, (b) feed hydrogen content $x$ with $\mathrm{H}_{2} / \mathrm{He} / \mathrm{N}_{2} /$ steam $=x: 10: 70-x: 20$ on the feed side at 5 bar and $\mathrm{Ar} / \mathrm{steam}=80: 20$ on the permeate side at 4.9 bar, and (c) feed steam content $y$ with $\mathrm{H}_{2} / \mathrm{He} / \mathrm{N}_{2} /$ steam $=20: 10: 50-y: y$ on the feed side at 5 bar and Ar/steam $=80: 20$ on the permeate side at 4.9 bars.

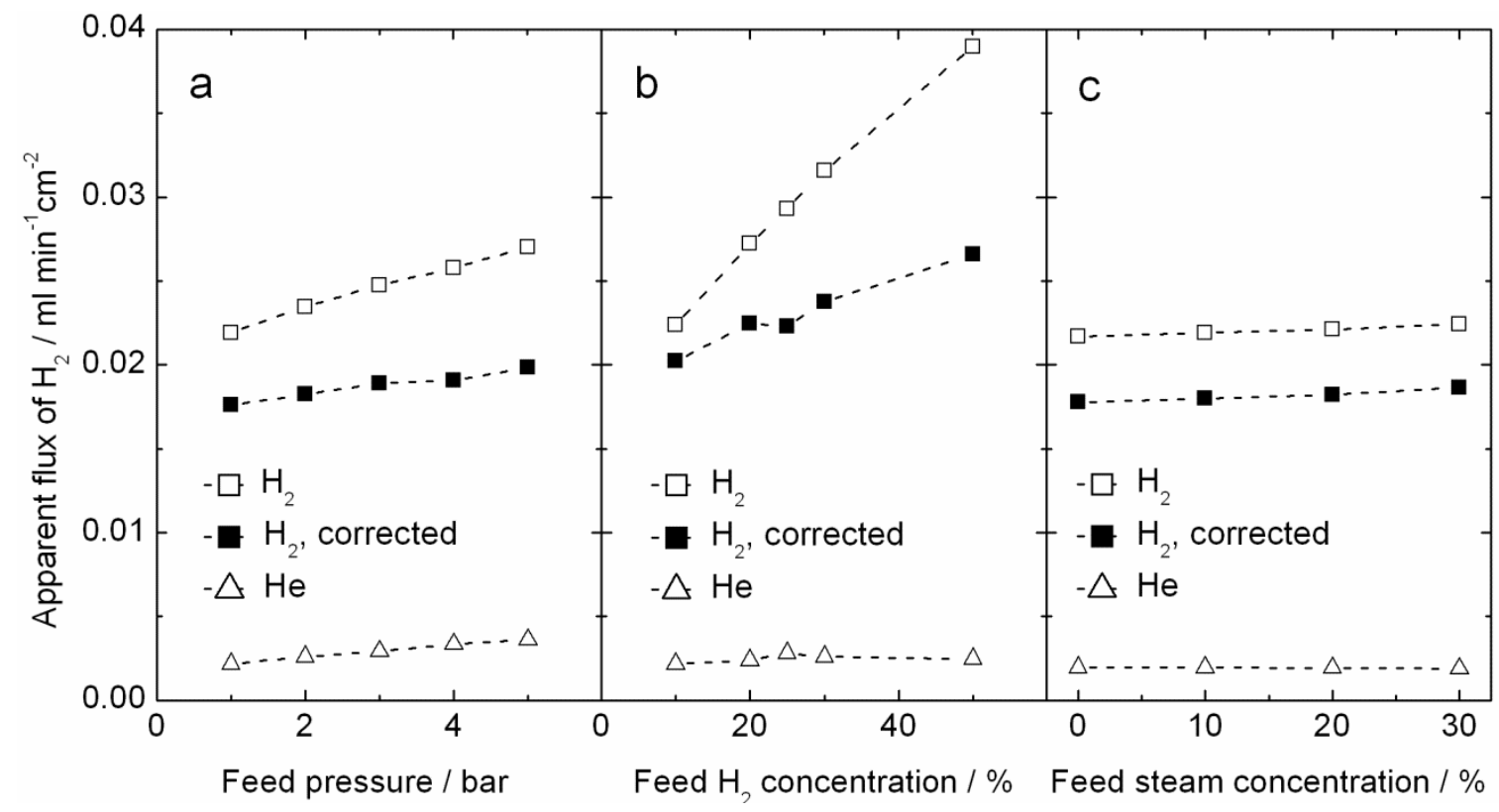

\subsection{Measurements of Hydrogen Production with Monolith Module under Pressurized Conditions}

The hydrogen production of an LSC monolith module was also tested at $1000-800{ }^{\circ} \mathrm{C}$ and 20 bars pressure in moist hydrogen. The monolith had 37 active channels: 21 for feed gas and 16 for permeate sweep gas. The dense membrane was applied on the porous walls in the monolith on the sweep channel side and had a thickness of $50 \mu \mathrm{m}$. The concentration of hydrogen in the permeate gas was $19 \%-22 \%$. Figure 11 shows the area specific hydrogen leakage and apparent hydrogen flux.

Accordingly, there is a considerable apparent flux through the membrane, and the leakage is low compared to the calculated apparent hydrogen flux. The measurements were performed with co-current flow of feed and sweep gas, rapidly decreasing the driving force for hydrogen permeation, and the gas feeding rate $(1000 \mathrm{~mL} / \mathrm{min})$ was also low compared to the high apparent flux and membrane area $\left(86 \mathrm{~cm}^{2}\right)$. Besides, the performance of the module was not tested with air on the sweep side, which would have served to maintain a high driving force throughout the monolith and increase the permeation of hydrogen, as mentioned in the introduction for the selected PCDC process. It is therefore expected that the module would perform even better under realistic conditions, e.g., counter-current flow regime with air at the sweep side. There is also room for decreasing the thickness of the membrane well below $50 \mu \mathrm{m}$. A hydrogen production rate of the order of $10 \mathrm{~mL} \mathrm{~cm}^{-2} \mathrm{~min}^{-1}$ under real operating conditions seems therefore to be within reach with this material. 
Figure 11. Apparent hydrogen flux and leakage of the monolith module at 20 bars pressure.

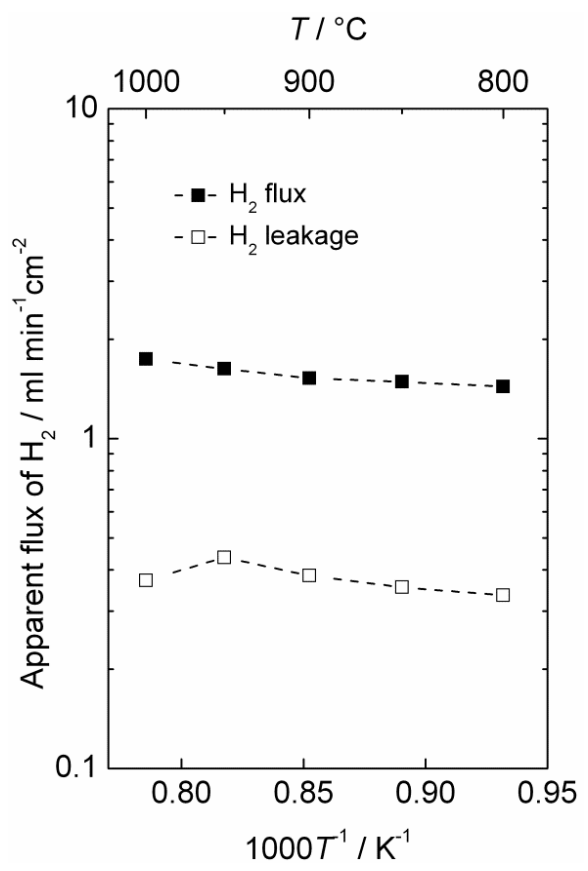

It may still be added that this experiment may also have had a large portion of the hydrogen produced coming from water splitting. The leakages were large enough to prevent a detailed analysis of the mass balances that could have answered this question.

We note that the apparent flux densities are now some two orders of magnitude larger than in the case of the polished disk samples and that the temperature dependency, i.e., activation energy, is now small. We speculate that the surface of the membrane applied inside the monolith channels is catalytically active compared to the polished disk surfaces, and that the results of the monolith reflect bulk limited diffusion, while those of the disk samples reflect surface kinetics limitations.

\subsection{Flux Measurements Using $\mathrm{D}_{2}$ and $\mathrm{D}_{2} \mathrm{O}$}

In order to unambiguously prove diffusion of hydrogen and perhaps quantify the possible contribution from water splitting on the permeate side of the membrane to the produced hydrogen, permeation measurements were carried out using $\mathrm{D}_{2}$ and $\mathrm{D}_{2} \mathrm{O}$ on the feed side of the membranes. Mass spectrometry was used to analyze the permeate gas exiting the cell. Results are plotted in Figure 12.

With dry permeate gas, the presence of only $\mathrm{D}_{2} \mathrm{O}$ on the feed side gives rise to very little $\mathrm{D}$-containing species in the permeate, showing that there is little $\mathrm{D}_{2} \mathrm{O}$ flux from ambipolar proton (here deuteron) and oxide ion transport, see Figure 12 (first hour). Introduction of $\mathrm{D}_{2}$ on the feed side gives a driving force for ambipolar deuteron-electron hole transport, and a large and dominating increase in the $\mathrm{D}_{2}$ content on the permeate side results. This proves unambiguously the presence of hydrogen flux due to ambipolar proton (here deuteron) and electron hole transport.

Experiments were also made with $\mathrm{H}_{2} \mathrm{O}$-wetted permeate gas. In this case, $\mathrm{D}_{2}$ in the permeate, originated from flux, will isotopically mix with $\mathrm{H}_{2} \mathrm{O}$, resulting in an increase in the concentration of species $\mathrm{HD}, \mathrm{HDO}, \mathrm{H}_{2}$ and $\mathrm{D}_{2} \mathrm{O}$, and a decrease in the concentration of $\mathrm{H}_{2} \mathrm{O}$, see Figure 13. 
Figure 12. Mass spectrometer signal from various masses $v s$. time, indicative of deuterium flux through LSC disk membrane at $1040{ }^{\circ} \mathrm{C}$ when changing the feed gas from $\mathrm{He}+2.5 \%$ $\mathrm{D}_{2} \mathrm{O}$ to $\mathrm{D}_{2}+2.5 \% \mathrm{D}_{2} \mathrm{O}$ after approximately 1 hour.

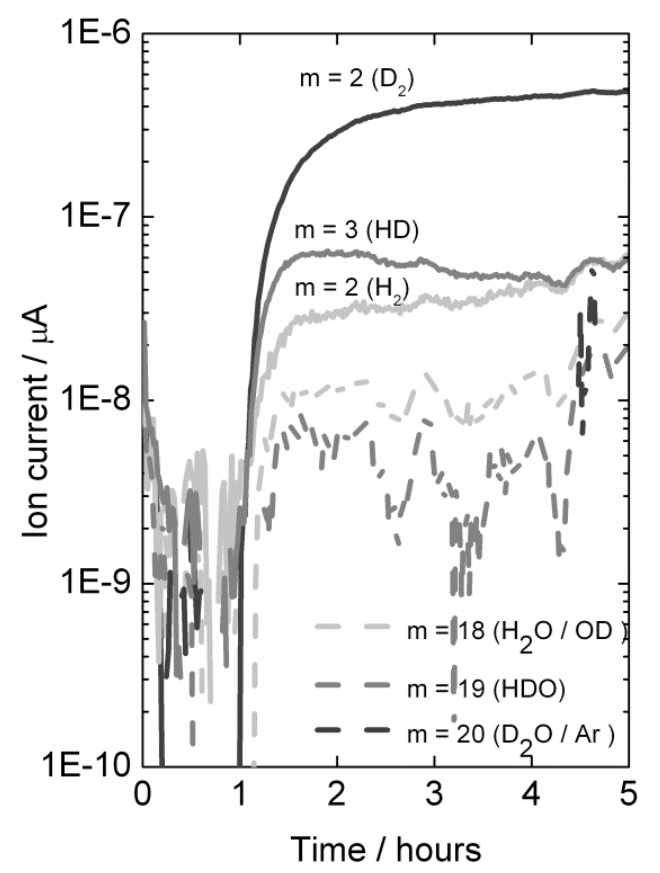

Figure 13. Mass spectrometer signal from various masses vs. time, indicative of deuterium flux through LSC disk membrane at $1040{ }^{\circ} \mathrm{C}$ when changing the feed gas from $\mathrm{He}+2.5 \%$ $\mathrm{D}_{2} \mathrm{O}$ to $\mathrm{D}_{2}+2.5 \% \mathrm{D}_{2} \mathrm{O}$ after approximately 2 hours. Permeate gas is $\mathrm{Ar}+2.5 \% \mathrm{H}_{2} \mathrm{O}$.

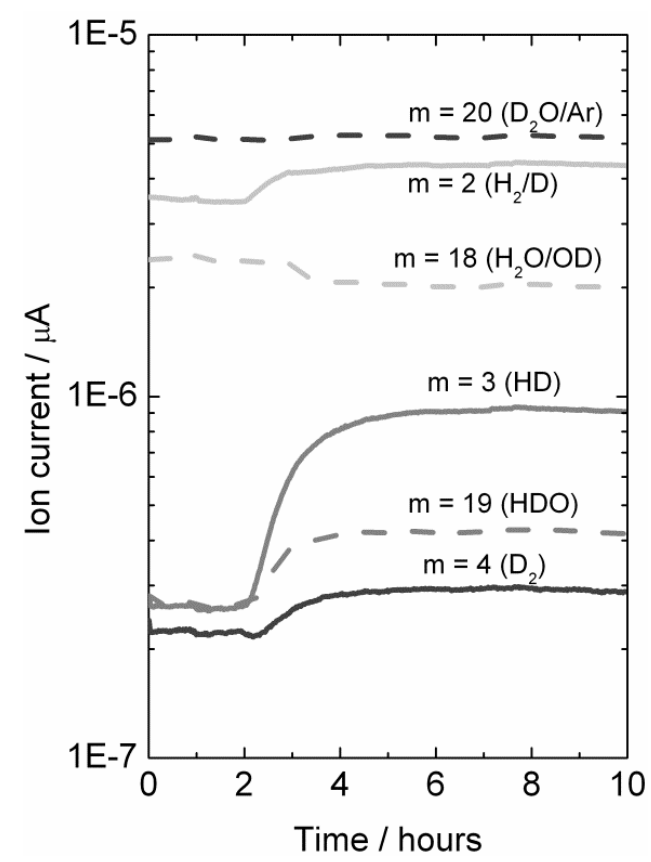

A mass balance analysis of the permeate flue gas for this experiment at $1040{ }^{\circ} \mathrm{C}$ results in around $80 \%$ of the hydrogen (here hydrogen and deuterium) produced comes from hydrogen (here deuterium) flux and that $20 \%$ comes from water splitting. 
It may be noted that the sample used here was again a polished disk membrane. The high level of hydrogen flux compared to water splitting suggests that although both processes may be surface kinetics limited, the water splitting is more limited by surface kinetics than the hydrogen flux is.

\subsection{Comparison of Data from Different Techniques}

Figure 14 presents the ambipolar proton-electron hole and oxygen vacancy-electron hole conductivities as a function of inverse temperature estimated from electrical measurements, the ambipolar proton-electron hole conductivity extracted from the measurements of hydrogen production with the disk membrane (wet and dry permeate gas), and the ambipolar proton-electron hole conductivity extracted from the measurements of hydrogen production with the monolith module (wet permeate gas).

Figure 14. Ambipolar proton-electron hole and oxygen vacancy-electron hole conductivity as a function of inverse temperature for $\mathrm{La}_{0.9} \mathrm{Sr}_{0.1} \mathrm{CrO}_{3-\delta}$, estimated from conductivity measurements, compared with conductivities extracted from measurements of hydrogen production with disk membrane in two different gradients and with the monolith module. All proton conductivities are extrapolated to $0.025 \mathrm{~atm} \mathrm{H}_{2} \mathrm{O}$.

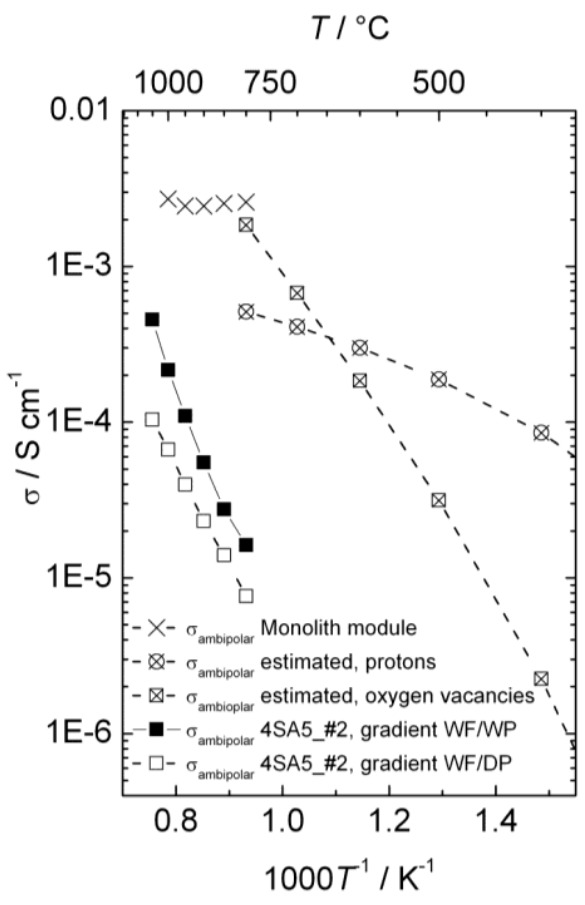

Two different models were used to describe the hydrogen flux and relate it to ambipolar conductivity for wet and dry permeate gas. Both assume that the transport number for electron holes is unity, so that ambipolar conductivity equals proton conductivity. For wet permeate gas (and wet feed gas) we assume that the hydration level and thus proton concentration is constant throughout the membrane. The difference in $\mathrm{pH}_{2}$ is the only driving force for hydrogen (proton) flux, and the following model is applied:

$$
j_{\mathrm{H}^{+}}=\frac{-R T \sigma_{\mathrm{H}^{+}}}{2 F^{2} L}\left[\ln p_{\mathrm{H}_{2}(\mathrm{~g})}^{\mathrm{II}}-\ln p_{\mathrm{H}_{2}(\mathrm{~g})}^{\mathrm{I}}\right]
$$


Here, the proton conductivity is the one valid for the $p \mathrm{H}_{2} \mathrm{O}$ used in the measurement, $L$ is the membrane thickness, and the other symbols have their usual meanings.

From the dry permeate case, we assume that the $p \mathrm{H}_{2} / p \mathrm{H}_{2} \mathrm{O}$ ratio is constant throughout the membrane, which is attained to a first approximation through ambipolar water flux accompanying the hydrogen flux. The proton conductivity is thus not constant throughout the membrane, and the following model is applied:

$$
j_{\mathrm{H}^{+}}=\frac{-R T \sigma_{\mathrm{H}^{+}, 0}}{F^{2} L}\left[\left(p_{\mathrm{H}_{2}(\mathrm{~g})}^{1 / 2}\right)^{\mathrm{II}}-\left(p_{\mathrm{H}_{2}(\mathrm{~g})}^{1 / 2}\right)^{\mathrm{I}}\right]
$$

Here $\sigma_{\mathrm{H}^{+}}=\sigma_{\mathrm{H}^{+}, 0} \times p \mathrm{H}_{2}{ }^{1 / 2}$ at the $p \mathrm{H}_{2} / p \mathrm{H}_{2} \mathrm{O}$ used. It may be noted that both models yield proton conductivities that are valid for a given water vapor content, which may be recalculated for another one assuming that the protons are minority defects and their concentration proportional to $p \mathrm{H}_{2} \mathrm{O}^{1 / 2}$, and this has been applied in plotting Figure 14.

While the models are uncertain, the choice of model does not dramatically alter the resulting proton conductivity.

Based on the knowledge of the defect structure and transport properties of LSC, the conductivity measurements, the $\mathrm{D}_{2}$ flux measurements and isotope exchange data, and the hydrogen production measurements from disk and monolith membranes, we may now tentatively conclude the following from our studies so far:

From the changes in p-type electronic conductivity with $p \mathrm{H}_{2} \mathrm{O}$, we know that LSC hydrates significantly and contains considerable concentrations of protons. The thermodynamics of hydration can be extracted, and we can make a first guess of the proton conductivity in LSC in wet atmospheres as a function of temperature and compare this with an estimate of the oxide ion conductivity which is based on more solid data (Figure 14). From this and the dominating p-type electronic conductivity we can predict that LSC will be permeable to hydrogen, oxygen, and water in gradients of $p \mathrm{H}_{2}, p \mathrm{O}_{2}$, and $p \mathrm{H}_{2} \mathrm{O}$. The two first can be used respectively for hydrogen production by hydrogen flux and water splitting.

The $\mathrm{D}_{2}$ flux measurements prove unambiguously that there is in fact hydrogen flux in the material. Moreover, they suggest that hydrogen flux and water splitting contribute within the same order of magnitude to the hydrogen production ( $80 \%$ and $20 \%$, respectively, for a disk sample at $1040{ }^{\circ} \mathrm{C}$ in wet gases).

Hydrogen production measurements using a monolithic membrane module with large area at high pressures and high steam contents yield a high output, one order of magnitude higher than estimated from the guessed proton conductivity, and with a small temperature dependency as predicted for hydrogen flux limited by bulk transport, see Figure 14. All in all, we suggest that this is to a large extent hydrogen flux, and that the protons therefore may have a higher mobility than guessed.

Hydrogen production measurements using polished disk samples show variations with atmosphere composition that support the simultaneous presence of hydrogen flux and water splitting. The activation energies are, however, consistently higher and the apparent flux lower than expected from the ambipolar conductivities (see Figure 14). This suggests that these samples are severely limited by surface kinetics. Based on this, the activation energy for surface kinetics is similar for both hydrogen flux and water splitting, although details in the results from the various experiments can be interpreted to reflect that water splitting is more limited by surface kinetics than hydrogen permeation. 
The monolith module demonstrated promising flux densities and hydrogen production rates, and appears to have been produced with relatively active surfaces.

Future studies of LSC membranes for hydrogen production must focus on the kinetics and engineering of its surfaces.

\section{Experimental Section}

\subsection{Samples Preparation}

The LSC powders were prepared by spray pyrolysis at $750{ }^{\circ} \mathrm{C}$ of an aqueous nitrate solution with chromium, strontium and lanthanum concentrations according to the perovskite stoichiometry. The solution contained 1 mole metal ions per liter, corresponding to approximately $115 \mathrm{~g}$ perovskite per liter. To retain maximum sintering activity and suppress the concentration and evaporation of carcinogenic $\mathrm{Cr}(\mathrm{VI})$, the powder was calcined in vacuum $(1 \mathrm{mbar})$ at $850{ }^{\circ} \mathrm{C}$. The powder was finally milled in a steel attrition mill for $120 \mathrm{~min}$ at $300 \mathrm{rpm}$ with $3 \mathrm{~kg}$ distilled water to $2 \mathrm{~kg} \mathrm{LSC}$. To increase sinterability, small additions (2-4 mol\%) of various partly-proprietary sintering aids were added during milling. Dilatometer studies of a powder batch with $2 \mathrm{~mol} \% \mathrm{CaMnO}_{3}$ demonstrated densities of $>95 \%$ by sintering in air at $1700{ }^{\circ} \mathrm{C}$ or in $4 \% \mathrm{H}_{2}$ in $\mathrm{N}_{2}$ at $1600{ }^{\circ} \mathrm{C}$. The latter condition was used for sample preparation, where the LSC powder with various sintering aids (Table 1) was pressed into green bodies and sintered to dense pellets.

Table 1. Overview of samples.

\begin{tabular}{ccccc}
\hline Short name & Composition & Sintering aid mol\% & Thickness [mm] & Diameter [mm] \\
\hline 2A_\#1 & $\mathrm{La}_{0.87} \mathrm{Sr}_{0.13} \mathrm{CrO}_{3}$ & $2(" \mathrm{~A} ")$ & 0.435 & 20 \\
4B_\#3 & $\mathrm{La}_{0.87} \mathrm{Sr}_{0.13} \mathrm{CrO}_{3}$ & $4(" \mathrm{~B} ")$ & 0.445 & 20 \\
4SA5_\#2 & $\mathrm{La}_{0.87} \mathrm{Sr}_{0.13} \mathrm{CrO}_{3}$ & $4\left(\mathrm{CaMnO}_{3}\right)$ & 0.550 & 20 \\
\hline
\end{tabular}

LSC powder with $2 \mathrm{~mol} \% \mathrm{CaMnO}_{3}$ was also used for fabrication of the small asymmetric monolithic membrane module. The support structure was a circular porous monolith, extruded from a mixture of LSC and pore former (20 wt \% cellulose fiber) with binder (methyl cellulose), plasticizer (polyethylene glycol) and water. The extruded monoliths were dried at $40{ }^{\circ} \mathrm{C}$, while a fan maintained air circulation through the channels. To remove the organic components, the dry monoliths were heated to $500{ }^{\circ} \mathrm{C}$ at a low rate of $0.1 \% \mathrm{~min}$ to avoid overheating and cracking. After a final pre-sintering of the support monolith at $1200{ }^{\circ} \mathrm{C}$, the LSC membrane was applied by dip coating with access to each second monolith channel in a chess pattern. After sintering in dilute hydrogen at $1700{ }^{\circ} \mathrm{C}$, the dense membrane layer was $50 \mu \mathrm{m}$ thick, and proved gas impervious at room temperature, while the channel width and wall thickness were 1.7 and $0.4 \mathrm{~mm}$, respectively.

Pictures of the membranes and the monolith have been published elsewhere [3]. The monolith had 37 active channels: 21 for feed gas and 16 for sweep gas. The membrane was applied in the sweep channels. The module was made from a $90 \mathrm{~mm}$ long monolith with $86 \mathrm{~cm}^{2}$ membrane area. To distribute feed and sweep gas in the appropriate channels, manifolds were sealed to the monolith at each end. Each manifold was made from a dense choke plate and gas distributor in LSC and a hat in yttrium stabilized zirconia. The components were sealed to each other by a glass ceramic with thermal 
expansion profile matching LSC. The module also had 2 gas baffles in platinum around the monolith, matching the inner diameter of the test reactor. During testing, the hats were sealed to $\mathrm{Al}_{2} \mathrm{O}_{3}$ support tubes by gold rings. Thus, the feed side of the membrane module was available from the inside of the supply tubes, while the sweep channels were available from the outside through the side holes of the gas distributor.

\subsection{Electrical Conductivity and Measurements of Hydrogen Production}

Electrical conductivity measurements in controlled atmospheres were performed on a $\mathrm{La}_{0.9} \mathrm{Sr}_{0.1} \mathrm{CrO}_{3}$-sample in a ProboStat ${ }^{\mathrm{TM}}$ cell (NorECs AS, Norway). The sample was rather porous - only $82 \%$ dense - in order to get a fast response with changes of atmosphere. An alternating current (a.c.), van der Pauw four point method, was used to measure the conductivity as a function of temperature and concentration of water vapor. The measurements were performed using a Solartron SI 1260 Frequency Response Analyzer operating at $1590 \mathrm{~Hz}$ and $1 \mathrm{~V}$ amplitude. The conductivity was not corrected for porosity, as this is a minor effect, and has no consequence for the interpretations used here. Different hydrogen-argon mixtures were used and the gas composition was controlled by gas mixing and wetting stages. The conductivity measurements were done under atmospheric pressure.

Measurements of hydrogen production of disk-shaped membranes were performed in a ProboStat ${ }^{\mathrm{TM}}$ cell, using planar polished samples and gold rings as seals. The support tubes were also polished, in order to improve the sealing process. Helium was used to verify successful sealing, indicated by $<0.01 \mathrm{~mol} \%$ detection of He using a gas chromatograph. Measurements were performed by using a humidified $\mathrm{He}: \mathrm{H}_{2}$ mixture (50:50 and 90:10) on the feed side (with a total of $50 \mathrm{~mL} / \mathrm{min}$ gas flow) and humidified Ar on the permeate side (with a gas flow of $25 \mathrm{~mL} / \mathrm{min}$ ). For pressurized measurements to 5 bars, the normal flow was multiplied by the pressure. Both $\mathrm{He}$ and $\mathrm{H}_{2}$ concentrations were measured with a calibrated Varian $4900 \mu$-GC. The apparent fluxes were calculated from the measured permeate $\mathrm{H}_{2}$ concentration and the calibrated flow of Ar sweep gas after correcting for He leak using a Knudsen ratio. For the pressurized flux measurements, a metal mantel was used on the ProboStat ${ }^{\mathrm{TM}}$ cell, which allowed measurement up to 30 bars at $900{ }^{\circ} \mathrm{C}$ or 10 bars at $1000{ }^{\circ} \mathrm{C}$. For mass spectrometry measurements, the permeate gas was analyzed with a Pfeiffer PrismaPlus QMG 220, and the spectrometer ion current converted to relative concentrations of species in the gas, based on several background and calibration runs of known gas mixtures.

Measurements of hydrogen production of the module were carried out in a different rig. The module was made from a $9 \mathrm{~cm}$-long monolith, which gave a total of $86 \mathrm{~cm}^{2}$ membrane area. It was installed in a reactor of Paralloy CR39W steel alloy, which is suited for test conditions involving high pressure, temperature and hydrogen activity. The feed gas was a mixture of $70 \% \mathrm{H}_{2}, 20 \%$ steam, and $10 \% \mathrm{~N}_{2}$, while the sweep gas was $80 \%$ Ar and $20 \%$ steam. At each side, the total flow rate was $1000 \mathrm{~mL} / \mathrm{min}$. After sealing the monolith module to the test reactor at $1000{ }^{\circ} \mathrm{C}$, only $0.5 \%$ nitrogen was detected in the sweep side flue gas in the entire temperature range.

\section{Conclusions}

In this study, we have evaluated the theoretical and empirical background for the potential use of acceptor-doped $\mathrm{LaCrO}_{3}$ as a hydrogen permeable membrane for hydrogen production, based on mixed 
proton and electron hole conductivity. We have also taken into account the possibility of oxygen permeation producing hydrogen from water splitting as a competing mechanism. We have reported on experimental studies of hydrogen production rates of LSC membranes prepared as dense polished discs and advanced monolithic geometry in various atmospheres, including pressurized conditions. Both gas chromatography and mass spectrometry using deuterium were carried out. The results confirm unambiguously that there is hydrogen flux by ambipolar proton and electron hole transport and show that oxygen transport and water splitting contribute. For the monolith module, the hydrogen fluxes are higher than predicted from estimates of proton conductivity, and have potential for further improvement (thinner membrane and better flow patterns), making LSC-based membranes promising for hydrogen production. Our studies indicate that surface kinetics easily become limiting for LSC for hydrogen permeation and probably even more so for water splitting, and studies of this and engineering of surfaces stand out as crucial in future developments.

\section{Acknowledgments}

This publication has been produced with support from the BIGCCS Centre, performed under the Norwegian research program Centres for Environment-friendly Energy Research (FME). The authors acknowledge the following partners for their contributions: Aker Solutions, ConocoPhillips, Det Norske Veritas, Gassco, Hydro, Shell, Statoil, TOTAL, GDF SUEZ and the Research Council of Norway (project No. 193816/S60). The authors acknowledge Stefan Marion for carrying out the conductivity measurements.

\section{References}

1. Middleton, P.; Hurst, P.; Walker, G. GRACE: Pre-Combustion De-Carbonisation Hydrogen Membrane Study. In Carbon Dioxide Capture for Storage in Deep Geologic Formations: Results from the $\mathrm{CO}_{2}$ Capture Project; Thomas, D.C., Benson, S., Eds.; Elsevier: Amsterdam, The Netherlands, 2005; Volume 1, pp. 409-425.

2. Beavis, R. The EU FP6 CACHET project—Final results. Energy Procedia 2011, 4, 1074-1081.

3. Smith, J.B.; Aasen, K.I.; Wilhelmsen, K.; Käka, D.; Risdal, T.; Berglund, A.; Stenersen Østby, A.; Budd, M.; Bruun, T.; Werswick, B. Recent development in the HMR pre-combustion gas power cycle. Energy Procedia 2009, 1, 343-351.

4. Fontaine, M.L.; Norby, T.; Larring, Y.; Grande, T.; Bredesen, R. Oxygen and hydrogen separation membranes based on dense ceramic conductors. Membr. Sci. Technol. 2008, 13, 401-458.

5. Norby, T.; Haugsrud, R. Dense Ceramic Membranes for Hydrogen Separation. In Nonporous Inorganic Membranes; Sammells, A.F., Mundschau, M.V., Eds.; WILEY-VCH Verlag GmbH \& Co. KGaA: Weinheim, Germany, 2006; pp. 1-48.

6. Davies, R.; Islam, M.; Gale, J. Dopant and proton incorporation in perovskite-type zirconates. Solid State Ionics 1999, 126, 323-335.

7. Norby, T.; Widerøe, M.; Glöckner, R.; Larring, Y. Hydrogen in oxides. Dalton Trans. 2004, 19, 3012-3018.

8. Norby, T. Proton Conductivity in Perovskite Oxides. In Perovskite Oxide for Solid Oxide Fuel Cells; Ishihara, T., Ed.; Springer US: New York, NY, USA, 2009; pp. 217-241. 
9. Bjørheim, T.S.; Kuwabara, A.; Ahmed, I.; Haugsrud, R.; Stølen, S.; Norby, T. A combined conductivity and DFT study of protons in $\mathrm{PbZrO}_{3}$ and alkaline earth zirconate perovskites. Solid State Ionics 2010, 181, 130-137.

10. Glöckner, R. Dissolution and Transport of Protons in Some Perovskite-Related Oxides. Ph.D Thesis, University of Oslo, Oslo, Norway, 27 October 2000.

11. Iwahara, H. Oxide-ionic and protonic conductors based on perovskite-type oxides and their possible applications. Solid State Ionics 1992, 52, 99-104.

12. Solís, C.; Escolastico, S.; Haugsrud, R.; Serra, J.M. La ${ }_{5.5} \mathrm{WO}_{12-\delta}$ characterization of transport properties under oxidizing conditions: A conductivity relaxation study. J. Phys. Chem. C 2011, $115,11124-11131$.

13. Julsrud, S.; Vigeland, B.E. A Solid Multicomponent Mixed Proton and Electron Conducting Membrane. EP Patent 1448293, 30 October 2007.

14. Aasen, K.; Vigeland, B.; Norby, T.; Larring, Y.; Mejdell, T. Development of a hydrogen membrane reformer based $\mathrm{CO}_{2}$ emission free gas fired power plant. Greenhouse Gas Control Technol. 7 2005, 1, 83-91.

15. Tezuka, K.; Hinatsu, Y.; Nakamura, A.; Inami, T.; Shimojo, Y.; Morii, Y. Magnetic and neutron diffraction study on perovskites $\mathrm{La}_{1-\mathrm{x}} \mathrm{Sr}_{\mathrm{x}} \mathrm{CrO}_{3}$. J. Solid State Chem. 1998, 141, 404-410.

16. Schneider, S.; Roth, R.; Waring, J. Solid state reactions involving oxides of trivalent cations. J. Res. Natl. Bur. Stand. 1961, 65A, 345-374.

17. Peck, D.; Miller, M.; Hilpert, K. Phase diagram study in the $\mathrm{CaO}-\mathrm{Cr}_{2} \mathrm{O}_{3}-\mathrm{La}_{2} \mathrm{O}_{3}$ system in air and under low oxygen pressure. Solid State Ionics 1999, 123, 47-57.

18. Peck, D.; Miller, M.; Hilpert, K. Phase diagram studies in the $\mathrm{SrO}-\mathrm{Cr}_{2} \mathrm{O}_{3}-\mathrm{La}_{2} \mathrm{O}_{3}$ system in air and under low oxygen pressure. Solid State Ionics 1999, 123, 59-65.

19. Zhu, W.; Deevi, S. Development of interconnect materials for solid oxide fuel cells. Mater. Sci. Eng. A 2003, 348, 227-243.

20. Mizusaki, J.; Yamauchi, S.; Fueki, K.; Ishikawa, A. Nonstoichiometry of the perovskite-type oxide $\mathrm{La}_{1-\mathrm{x}} \mathrm{Sr}_{\mathrm{x}} \mathrm{CrO}_{3}$-[delta]. Solid State Ionics 1984, 12, 119-124.

21. Flandermeyer, B.; Nasrallah, M.; Agarwal, A.K.; Anderson, H. Defect structure of mg-doped lacro $_{3}$ model and thermogravimetric measurements. J. Amer. Ceram. Soc. 1984, 67, 195-198.

22. Yasuda I, H.T. In Electrical Conductivity and Oxygen Chemical Diffusion Coefficients of Calcium-Doped Lanthanum Chromites, Second International Symposium on Solid Oxide Fuel Cells; Grosz F, Z.P., Singahl, S.C., Yamamoto, O., Eds.; Commision of the European Community: Athens, Greece, 1991; pp. 645-652.

23. Yasuda, I.; Hikita, T. Electrical conductivity and defect structure of calcium-doped lanthanum chromites. J. Electrochem. Soc. 1993, 140, 1699-1704.

24. Fergus, J.W. Materials challenges for solid-oxide fuel cells. JOM J. Min. Metal. Mater. Soc. 2007, $59,56-62$.

25. Koc, R.; Anderson, H.U. Liquid phase sintering of $\mathrm{LaCrO}_{3}$. J. Eur. Ceram. Soc. 1992, 9, $285-292$.

26. Hilpert, K.; Das, D.; Miller, M.; Peck, D.; Weiss, R. Chromium vapor species over solid oxide fuel cell interconnect materials and their potential for degradation processes. J. Electrochem. Soc. 1996, $143,3642-3647$. 
27. Yokokawa, H.; Sakai, N.; Horita, T.; Yamaji, K. Recent developments in solid oxide fuel cell materials. Fuel Cells 2001, 1, 117-131.

28. Paulik, S.; Baskaran, S.; Armstrong, T. Mechanical properties of calcium-and strontium-substituted lanthanum chromite. J. Mater. Sci. 1998, 33, 2397-2404.

29. Fergus, J.W. Metallic interconnects for solid oxide fuel cells. Mater. Sci. Eng. A 2005, 397, 271-283.

30. Yasuda, I.; Hishinuma, M. Electrochemical properties of doped lanthanum chromites as interconnectors for solid oxide fuel cells. J. Electrochem. Soc. 1996, 143, 1583-1590.

31. Karim, D.; Aldred, A. Localized level hopping transport in $\mathrm{La}(\mathrm{Sr}) \mathrm{CrO}_{3}$. Phys. Rev. B 1979, 20, 2255-2263.

32. Yokokawa, H.; Horita, T.; Sakai, N.; Hassel, B. Oxygen Permeation and Related Phenomena of Lanthanum Calcium Chromites as SOFC Interconnects. In Proceedings of the 3rd International Symposium on Solid Oxide Fuel Cells, Honolulu, HI, USA, 1993; pp. 364-373.

33. Van Hassel, B.A.; Kawada, T.; Sakai, N.; Yokokawa, H.; Dokiya, M. Oxygen permeation modelling of $\mathrm{La}_{1-y} \mathrm{Ca}_{y} \mathrm{CrO}_{3-\delta}$. Solid State Ionics 1993, 66, 41-47.

34. Kawada, T.; Horita, T.; Sakai, N.; Yokokawa, H.; Dokiya, M. Experimental determination of oxygen permeation flux through bulk and grain boundary of $\mathrm{La}_{0.7} \mathrm{Ca}_{0.3} \mathrm{CrO}_{3}$. Solid State Ionics 1995, 79, 201-207.

35. Weber, W.J.; Griffin, C.W.; Bates, J.L. Effects of cation substitution on electrical and thermal transport properties of $\mathrm{YCrO}_{3}$ and $\mathrm{LaCrO}_{3}$. J. Amer. Ceram. Soc. 1987, 70, 265-270.

(C) 2012 by the authors; licensee MDPI, Basel, Switzerland. This article is an open access article distributed under the terms and conditions of the Creative Commons Attribution license (http://creativecommons.org/licenses/by/3.0/). 